\title{
O que é "Meio Ambiente"? Transversalizando a educação ambiental no ensino de Biologia a partir de atividades investigativas
}

What is environment"? Transversalizing environmental education in Biology teaching from investigative activities

Marisa Cristina Pinto ${ }^{1}$, Diógina Barata ${ }^{2}$, Marcos da Cunha Teixeira ${ }^{2}$

${ }^{1}$ Programa de Pós-Graduação em Rede em Ensino de Biologia (PROFBIO), Universidade Federal do Espírito Santo, São Mateus, Espírito Santo, Brasil.

${ }^{2}$ Universidade Federal do Espírito Santo, Departamento de Ciências Agrárias e Biológicas, São Mateus, Espírito Santo, Brasil.

Autor para correspondência: Marisa Cristina Pinto

EEEFM Silvio Rocio

Rua Assunção, 96, Araças, CEP 29.103-280, Vila Velha, Espírito Santo, Brasil

Tel: +55 27 99257-6621

Email: marisacristina813@gmail.com

Submetido em 21/12/2020

Aceito em 21/12/2020 


\title{
RESUMO
}

O trabalho trata-se de uma proposta de atividade investigativa sobre o tema Educação Ambiental para as aulas de Biologia do ensino médio, tendo como objetivo desenvolver atividade investigativa para transversalização da educação ambiental no ensino de Biologia. O trabalho procurou interagir o uso do celular, a educação ambiental e o ensino por investigação do processo de ensino e aprendizagem por meio de uma sequência didática. Esses três elementos contribuíram para tornar o ensino de biologia mais próximo da realidade dos estudantes.

Palavras-chave: Biologia. Educação Ambiental. Atividade Investigativa. Sequência Didática. Ensino.

\begin{abstract}
The work is a proposal for an investigative activity on the theme of Environmental Education for Biology classes in high school aiming to develop investigative activity for the transversalization of environmental education in the teaching of Biology. The work sought to interact the use of cell phones, environmental education and teaching by investigation of the teaching and learning process through a didactic sequence. These three elements contributed to bring the teaching of biology closer to the students' reality.
\end{abstract}

Keywords: Biology. Environmental Education. Investigative Activity. Following Teaching. Teaching.

Health and Biosciences, v.1, n.3, Dez. 2020

Disponível em: https://periodicos.ufes.br/healthandbiosciences 


\section{INTRODUÇÃO}

Diante dos avanços recentes é difícil imaginar para onde as tecnologias de informação e comunicação (TIC) irão nos levar. Para entendermos esse complicado processo evolutivo da comunicação, o foco deve ser em quem a está usando e como está usando. Assim, poderemos entender a influência dessas TIC nas formas de comunicação e, consequentemente, no aprendizado que dela decorre. Nesse contexto, é importante que a escola se aproprie das TICs com o objetivo de utilizá-las como instrumentos auxiliares para tornar o processo de ensino e aprendizagem mais adequado à realidade dos estudantes e, portanto, mais eficiente.

Segundo Belloni (2012, p. 05),

Os modos de acesso ao conhecimento de amanhã são difíceis de imaginar e, então, o melhor caminho será centrar o foco no utilizador (usuário) por duas razões logicamente necessárias: entender como funciona esta autodidaxia para adequar métodos e estratégias de ensino; assegurar que não se percam de vista as finalidades maiores da educação, ou seja, formar o cidadão competente para a vida em sociedade o que inclui a apropriação crítica e a criativa de todos os recursos técnicos à disposição desta sociedade.

Considerando que o celular representa uma tecnologia presente no cotidiano dos estudantes relatamos aqui uma experiência de sua utilização em uma atividade investigativa envolvendo conteúdos de Biologia e Educação Ambiental. A atividade utilizou-se da produção de fotografias feitas com os celulares dos estudantes como ponto de partida para observação do ambiente e (re) significação da percepção dos alunos acerca do lugar em que vivem. Deste modo, a atividade representou uma forma de transversalização da educação ambiental na disciplina de biologia no ensino médio.

A educação ambiental, em seu caráter transdisciplinar, permite abarcar diversos conteúdos do currículo das Ciências Biológicas no ensino médio e, ao mesmo tempo, promover a formação crítica dos estudantes. Reigota (2014, p. 30) destaca que "A Educação Ambiental serve para desenvolver nos alunos atitudes que irão ser benéficas para o ambiente, pois o aluno passará a compreender a importância do meio ambiente para sua existência”. Dessa forma, a escola cumpre seu papel na formação do sujeito ecológico, necessário ao processo de construção da sustentabilidade. Segundo Carvalho (2004, p. 65), “o sujeito ecológico é um ideal de ser que condensa a utopia de uma existência ecológica plena, que também implica uma sociedade plenamente ecológica". Carvalho, após estudar o processo de formação do sujeito ecológico, conclui que no processo de construção desse sujeito "o ideal de ser e de viver em um mundo 
ecológico se vai constituindo como um parâmetro orientador das decisões e que [...] as pessoas que aderem a esses ideais vão incorporando em suas vidas cotidianas” (p. 65).

No âmbito do ensino formal, essa incorporação de atitudes e comportamentos, individuais e coletivos, em prol do processo de construção da sustentabilidade deve se pautar também pela formação científica. Segundo Libâneo (2011) a aprendizagem não acontece sem a aprendizagem dos conhecimentos científicos das respectivas disciplinas escolares. Esse conhecimento só pode acontecer via escola, compreendida como o espaço para constituir a sociedades do conhecimento, capaz de acompanhar o desenvolvimento contemporâneo (PEREIRA \& CARLOTO, 2016). É a partir dessa perspectiva, balizada na relação entre os princípios da educação ambiental e do ensino de Biologia em uma perspectiva investigativa, que a experiência aqui relatada foi concebida. Sasseron (2015, p. 58) explica que

\begin{abstract}
O ensino por investigação extravasa o âmbito de uma metodologia de ensino apropriada apenas a certos conteúdos e temas, podendo ser colocada em prática nas mais distintas aulas, sob as mais diversas formas e para os diferentes conteúdos. Denota a intenção do professor em possibilitar o papel ativo de seu aluno na construção de entendimento sobre os conhecimentos científicos. Por esse motivo, caracteriza-se por ser uma forma de trabalho que o professor utiliza na intenção de fazer com que a turma se engaje com as discussões e, ao mesmo tempo em que travam contato com fenômenos naturais, pela busca de resolução de um problema, exercitam práticas e raciocínios de comparação, análise e avaliação bastante utilizadas na prática científica.
\end{abstract}

Nessa abordagem didática (SASSERON, 2015) espera-se que o estudante atinja o mais alto nível no estudo da Biologia e que utilize os conhecimentos no seu dia a dia. "Nesse sentido, a vida cotidiana oferece uma gama de oportunidades que podem ser exploradas do ponto de vista dos conceitos biológicos" (SCARPA \& CAMPOS, 2018 p. 09). Porém, o que se observa, com certa frequência, é que os conteúdos são trabalhados de forma desvinculada da realidade, dos aspectos históricos e das questões sociais. Assim, buscou-se oportunizar aos estudantes a observação dos ambientes que fazem parte de seu cotidiano e registrar aspectos dos mesmos em fotografias que serviram de ponto de partida para o desenvolvimento da atividade relatada a seguir.

\title{
OBJETIVOS
}

Desenvolver atividade investigativa para transversalização da educação ambiental no ensino de Biologia.

Health and Biosciences, v.1, n.3, Dez. 2020 


\section{Objetivos específicos}

$\checkmark$ Possibilitar o uso das tecnologias da informação no ensino de Biologia;

$\checkmark$ Transversalizar a educação ambiental no ensino de Biologia;

$\checkmark$ Desenvolver o espírito investigativo nos estudantes.

\section{METODOLOGIA}

\section{Materiais utilizados}

- Celulares com câmeras fotográficas;

- Data show;

- Sementes de plantas nativas da Mata Atlântica;

- Mudas de plantas nativas da Mata Atlântica;

\section{Desenvolvimento}

A fase inicial de um projeto didático representa um dos momentos mais importantes, pois dele dependerá todo o seu desenvolvimento. Nessa fase, a forma como o professor aborda o problema poderá significar o engajamento ou a desmotivação dos alunos. Nesse sentido, a abordagem deve ter como meta ajudar os alunos a perceberem que são parte determinante para que o projeto aconteça.

$\mathrm{Na}$ presente proposta utilizou-se, no primeiro encontro (duas aulas), da exibição do filme “A história das Coisas" (título original: Story of Stuff, direção de Louis Fox, gênero documentário, 2007). O documentário aborda as questões ambientais de forma crítica a partir do ciclo de vida dos produtos que utilizamos no nosso dia a dia. Para isso, propõe uma reflexão sobre nossos hábitos de consumo, suas consequências sociais, econômicas e ambientais. Após a exibição do vídeo estabeleceu-se um debate com a turma, de forma a permitir que os alunos explicitassem seus pontos de vistas sobre o documentário. $\mathrm{O}$ debate serviu como instrumento para avaliar o grau de engajamento dos alunos com o tema. Como foi possível perceber um clima de grande participação da turma, a professora então propôs aos alunos o desenvolvimento de uma atividade em que a produção de conhecimentos fornecesse elementos para uma reflexão sobre o ambiente em que vivem.

A partir da aceitação dos alunos para se engajarem na atividade, a professora deu início ao estudo da percepção ambiental dos estudantes por meio da seguinte pergunta geradora: o que

Health and Biosciences, v.1, n.3, Dez. 2020

Disponível em: https://periodicos.ufes.br/healthandbiosciences 


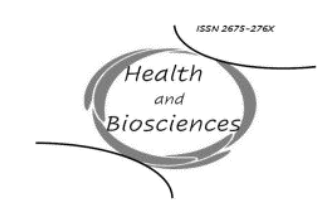

é meio ambiente? No entanto, para responderem a esta questão os alunos foram incentivados a utilizarem seus celulares ou câmeras para registrarem em fotografia uma imagem do entorno da escola ou em sua comunidade que representasse o meio ambiente para ele. Em seguida, deveriam elaborar um texto explicando os motivos que o levaram a escolher a imagem registrada. As imagens com os respectivos textos deveriam ser enviadas para a professora via e-mail ou WhatsApp. Com esta orientação finalizou-se o primeiro encontro. Todos os 26 alunos cumpriram a atividade e enviaram suas imagens e seus textos para a professora. A figura 1 apresenta algumas das imagens com as respectivas explicações dos alunos.
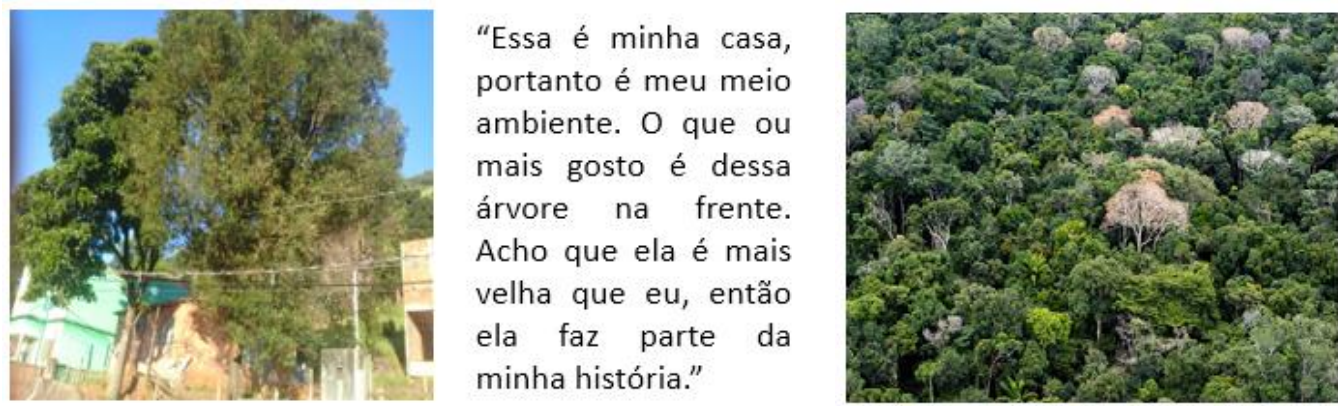

"Eu escolhi essa imagem por que ela foi tirada aqui em São Torquato me lembra o meio ambiente por que tem áreas Verdes"

Figura 1. Fotografias e textos produzidos por estudantes do ensino médio para representarem suas percepções sobre meio ambiente e respectivas explicações.

Os textos enviados pelos alunos foram submetidos à análise de conteúdo (BARDIN, 2011) adotando-se as concepções identificadas por Sauvé (1996). O quadro 1 apresenta as 4 concepções identificadas nos discursos dos estudantes, dentre as 6 indicadas por Sauvé (1996). As fotografias e suas explicações foram organizadas em slides pela professora e alguns alunos que se voluntariaram para ajudar neste trabalho. Assim, no segundo encontro ( 2 aulas), com uso de um projetor de slides, foi realizado um seminário no qual cada autor apresentou sua foto e sua concepção de ambiente. A partir das concepções dos alunos (Quadro 1) a professora foi fazendo as intervenções necessárias para que os estudantes pudessem compreender que o tema meio ambiente envolve aspectos multidimensionais para além de suas concepções apresentadas na Quadro 1. 
Quadro 1. Concepções de meio ambiente presente nos discursos dos estudantes de ensino médio conforme as tipologias propostas por Sauvé (1996a).

\begin{tabular}{|c|c|c|}
\hline $\begin{array}{c}\text { Concepção de meio } \\
\text { ambiente }\end{array}$ & Texto dos alunos & Total \\
\hline $\begin{array}{l}\text { Como lugar para } \\
\text { viver }\end{array}$ & $\begin{array}{l}\text { "Eu considero como meio ambiente aonde eu moro (...)" (A1). } \\
\text { "Isso faz esse ser um bom lugar por ter várias vegetações formando-se } \\
\text { assim o meio ambiente em que vivemos" (A5). } \\
\text { "Essa é uma rua do meu bairro que é também o meu meio ambiente" } \\
\text { (A12). } \\
\text { "Este é o meio ambiente onde eu vivo" (A15). } \\
\text { "É meu meio ambiente por que é a rua que passo todos os dias para ir para } \\
\text { a escola. Faz parte da minha vida e da minha história" (A21). } \\
\text { "É o visual que vejo da minha casa, então é o meu meio ambiente" (A22). } \\
\text { "Esse é o ambiente que vejo da minha casa" (A23). } \\
\text { "(...) uma pedra rolou e destruiu algumas casas no morro. Foi muito triste, } \\
\text { mas isso faz parte do ambiente onde eu moro" (A24). } \\
\text { "Essa é minha casa, portanto é meu meio ambiente" (A25). }\end{array}$ & 9 \\
\hline Como Biosfera & $\begin{array}{l}\text { "Ver os seres humanos e a natureza em comunhão é a forma mais bela de } \\
\text { representar o meio ambiente para mim" (A9). } \\
\text { "Cuidar do meio ambiente é fundamental para manter a saúde do nosso } \\
\text { planeta e de todos os seres vivos" (A19). } \\
\text { "O meio ambiente envolve todas as coisas com e sem vida que existem na } \\
\text { Terra e em todos os lugares dela" (A20). } \\
\text { "O motivo da imagem é o verde e o azul que me fazem lembrar da relação } \\
\text { da vida e da cor que existem em conjunto" (A16). } \\
\text { "Este me lembra o meio ambiente porque há vida" (A17). }\end{array}$ & 5 \\
\hline Como natureza & $\begin{array}{l}\text { "Eu escolhi essa imagem por que ela foi tirada aqui em São Torquato me } \\
\text { lembra o meio ambiente por que tem áreas Verdes" (A3), } \\
\text { "Eu escolhi essa imagem porque é do meu antigo bairro e me lembra a } \\
\text { Amazônia" (A4). } \\
\text { "Me lembra o meio ambiente por que tem áreas Verdes e um lindo mar e } \\
\text { serras do Espírito Santo" (A10). } \\
\text { "Essa imagem me lembra natureza pois tem muitas árvores e plantas ao } \\
\text { redor e por ser um lugar totalmente verde e agradável" (A13). } \\
\text { "Eu escolhi essa imagem por que ela me lembra muito o meio ambiente por } \\
\text { que ela me traz à memória a Amazônia que por sua vez, é o uns dos pulmões } \\
\text { do mundo e também ela faz parte da minha região, um ambiente de } \\
\text { natureza" (A14). } \\
\text { "Nesta imagem podemos ver uma mistura de ambientes onde a área urbana } \\
\text { se mistura com as arvores que são ambientes naturais que não foi } \\
\text { modificado pelo homem" (A 2). } \\
\text { Meio ambiente é um conjunto de unidades ecológicas (...) toda a vegetação, } \\
\text { animais, microrganismos, solo, rochas, atmosfera e fenômenos naturais que } \\
\text { podem ocorrer em seus limites" (A18). }\end{array}$ & 7 \\
\hline $\begin{array}{l}\text { Meio ambiente é um } \\
\text { problema a ser } \\
\text { solucionado }\end{array}$ & $\begin{array}{l}\text { "O lixo precisa ser armazenado (...) pode até prejudicar a comunidade com } \\
\text { essa quantidade de lixo acumulado" (A6). } \\
\text { "Temos esgotos não tratados que acabam desaguando nas ruas, mas tudo } \\
\text { isso forma o meio ambiente" (A7). } \\
\text { "A poluição é um grave problema (...). Isso, nos próximos anos poderá } \\
\text { extinguir toda vida pertencente a terra" (A8). } \\
\text { "Os moradores realizam muitas queimadas nessa área verde e destroem as } \\
\text { árvores interferindo no ambiente e na saúde e vida daqueles que vivem ali" } \\
\text { (A11). }\end{array}$ & 4 \\
\hline
\end{tabular}

Health and Biosciences, v.1, n.3, Dez. 2020

Disponível em: https://periodicos.ufes.br/healthandbiosciences 


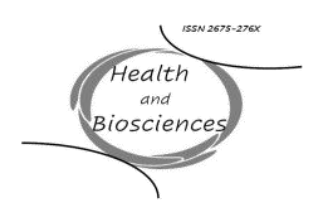

Ao final do seminário o grupo foi desafiado a indicar quais as questões comuns a todas as fotografias e a elaborar explicações sobre as ideias de meio ambiente apresentadas a partir das fotografias. Dentre as questões comuns levantados a professora solicitou que debatessem e indicassem aquela de maior importância para o grupo. Ao final do debate concluiu-se que o apego às árvores estava presente em todas as indicações e que a falta de arborização na comunidade e no entorno da escola era a questão mais relevante para o grupo no que se refere ao meio ambiente. Assim, decidiu-se que este seria o tema das próximas aulas.

No terceiro encontro uma nova pergunta geradora foi colocada pela professora: O que podemos fazer a respeito da falta de arborização da comunidade? Surgiu a ideia "podemos plantar árvores". Mas, que tipo de árvore? No primeiro momento a ideia que imperou foi plantar árvores frutíferas. Diante disso, a professora vislumbrou a possibilidade de envolver os estudantes em uma ação de investigação e encaminhou os alunos ao laboratório de informática com o propósito de pesquisarem os procedimentos e conceitos envolvidos nos processos de recuperação de áreas degradadas na Mata Atlântica. Entre as descobertas, compreenderam que muitas árvores frutíferas são exóticas e que os projetos de restauração devem priorizar as espécies nativas. Após uma discussão sobre os processos ecológicos e genéticos envolvidos nessa questão concluiu-se pela necessidade de uma aula de botânica sobre a reprodução de espécies nativas da mata atlântica. Além disso, decidiu-se por uma aula extraclasse em um viveiro de plantas nativas que foi realizada no quarto encontro.

A quarta aula ocorreu, como planejado com os alunos, em um viveiro, com acompanhamento de um monitor que explicou a forma de plantio, o processo de germinação das espécies e as principais características de cada espécie. Neste encontro foi abordada, também, a importância ecológica das plantas e a necessidade das árvores em locais de encostas e morros como prevenção de processos erosivos. Nesse momento alguns alunos lembraram que uma pedra rolou na comunidade e que provavelmente não teria ocorrido o desastre se existissem mais árvores plantadas. $\mathrm{O}$ viveiro doou mudas e sementes para os alunos, que mesmo sabendo que a planta levará anos para se tornar uma árvore, resolveram que realizariam o plantio desses espécimes em alguns locais da comunidade. A aula foi fotografada e registrada através de vídeos e anotações realizados pelos alunos.

No quinto encontro foi realizado o plantio das mudas e sementes obtidas no viveiro de plantas nativas. O local do plantio de cada muda foi escolhido pelos alunos, após uma reunião realizada entre a professora e os alunos participantes. Assim, ficou determinado que o plantio

Health and Biosciences, v.1, n.3, Dez. 2020

Disponível em: https://periodicos.ufes.br/healthandbiosciences 
de cada muda fosse fotografado ou filmado para que todos pudessem tomar ciência do fato. As sementes foram plantadas em vasos que permaneceram na escola para que todos pudessem observar o desenvolvimento e também serão plantadas na comunidade após a germinação.

\section{ASPECTOS INVESTIGATIVOS DA ATIVIDADE}

O primeiro aspecto investigativo a ser observado foi a motivação dos estudantes em buscar responder à questão "o que é meio ambiente". A professora não ofereceu uma resposta pronta, mas envolveu os estudantes em um processo que partiu de suas próprias concepções rumo à (re)elaboração do conceito.

O segundo ponto que deve ser ressaltado foi o protagonismo dos alunos em pesquisarem os procedimentos envolvidos nos processos de recuperação de áreas degradadas para responder à questão de quais espécies deveriam ser plantadas. A partir dessa atitude os estudantes puderam estudar diversos conteúdos como ecologia, reprodução vegetal e genética.

\section{CONSIDERAÇÕES}

A experiência relatada acima procurou interagir três elementos do processo de ensino e aprendizagem por meio de uma sequência didática: (1) o uso do celular, TI mais presente no cotidiano dos estudantes, (2) a educação ambiental, como forma de transversalizar o tema meio ambiente no ensino de biologia e (3) elementos do ensino por investigação, necessários para o desenvolvimento de atitudes científicas.

A sequência didática permitiu aos estudantes refletirem sobre suas concepções de meio ambiente, pois puderam compreender que o conceito de meio ambiente não é sinônimo de natureza ou ecologia, mas representa o encontro desses elementos com aspectos sociais, culturais e econômicos. A partir de um olhar investigativo puderam compreender as relações entre os conteúdos da biologia e as possibilidades de melhoria da qualidade do ambiente em que vivem. Além disso, pode-se perceber que por meio da atividade os estudantes apresentaram um comportamento mais participativo, pois após detectarem um problema socioambiental se posicionaram por uma intervenção por meio do plantio de árvores.

Conclui-se que o uso dos elementos de TI e dos objetivos da educação ambiental

Health and Biosciences, v.1, n.3, Dez. 2020

Disponível em: https://periodicos.ufes.br/healthandbiosciences 
integrados a uma sequência didática pautada em uma ação investigativa contribuiram para tornar o ensino de biologia mais próximo da realidade dos estudantes.

\section{AGRADECIMENTOS}

O presente trabalho foi realizado com o apoio da Coordenação de Aperfeiçoamento de Pessoal de Nível Superior - Brasil (CAPES) - Código de financiamento 001.

\section{REFERÊNCIAS BIBLIOGRÁFICAS}

1. BELLONI ML. O que é mídia-educação, 3.ed., Campinas: Autores Associados, 2009, 102p.

2. CARVALHO IC de M. Educação Ambiental: a formação de sujeito ecológico, São Paulo: Cortez, 2004, 256p

3. BARDIN L. Análise de conteúdo, São Paulo: Edições 70, 2011, 229 p

4. LIBÂNEO JC. Pedagogia e Pedagogos, para Quê?, 11ed., São Paulo: Cortez, 2011, 208p.

5. PEREIRA CMRB, CARLOTO DR. Reflexões sobre o papel social da escola. Rev Est Pesq Ens Geografia 3(4): 3-11, 2016.

6. REIGOTA M. O que é Educação Ambiental, 2.ed., São Paulo: Brasiliense, 2014, 112p.

7. SAUVÉ L. Environmental education and sustainable development: a further appraisal. CJEE 1(1): 7-34, 1996.

8. SASSERON LH. Alfabetização científica, ensino por investigação e argumentação: relações entre ciências da natureza e escola. Rev Ensaio 17(especial): 49-67, 2015.

9. SCARPA DL, CAMPOS NF. Potencialidades do ensino de Biologia por Investigação. Rev Est Avançados 32(94): 25-41, 2018. 